\title{
Leopoldo Querol i el seu lloc en el pianisme espanyol del segle $\mathrm{xx}^{1}$
}

\author{
MARio MAsó Agut (mariomaso@gmail.com) \\ Conservatori Professional de Música Mestre Tàrrega de Castelló
}

Si ens atenim a la màxima que afirma que la millor història s'escriu a través del que es reflecteix en la premsa de l'època, davant de Leopoldo Querol Roso estem, sens dubte, no només davant del millor pianista nascut a la província de Castelló, sinó davant d'un dels més grans intèrprets espanyols del segle xx.

A aquesta faceta interpretativa, que el va situar en un lloc preferent en el piano nacional del segon terç del segle, a la que cal sumar la seua trajectòria docent i musicològica, li podem afegir el seu paper de referència pel que fa a la vida cultural i musical de Castelló. Per exemple, Querol és l'intèrpret amb nombre més gran d'actuacions en entitats senyeres com la Societat Filharmònica de Castelló o el primer solista a actuar junt amb la Banda Municipal de la ciutat, o altres qüestions que poden anar des de la seua labor en pro de l'estrena de l'òpera La filla del Rei Barbut, de Matilde Salvador a, possiblement, el seu fet més conegut, la seua labor en la gènesi i desenvolupament del Certamen Internacional de Guitarra Francisco Tárrega, que ja ha superat la quaranta-cinquena edició.

\section{Infància i joventut}

Leopoldo Querol Roso va nàixer el dia 15 de novembre de 1899 al domicili familiar de la plaça Jovellar de Vinaròs, en el si d'una família paterna amb forta tradició comercial i política, i una materna amb gran component cultural i, especialment, musical.

Leopoldo va realitzar els seus primers estudis al seu Vinaròs natal, incloent-hi els musicals, de la mà de Matías Muñoz, el qual el va preparar per a l'ingrés en el Conservatori de València (Querol, 1971). L'examen d'ingrés es va realitzar el 26 d'octubre de 1909, i va aconseguir aprovar, en aquest, els dos primers cursos de piano i solfeig, i va accedir-hi, per tant, ja directament a tercer. ${ }^{2}$

Durant el curs 1911-1912 els Querol Roso van traslladar el seu domicili de Vinaròs a València; a partir de tot això, Leopoldo pot seguir els seus estudis al Conservatori ja com a alumne oficial, així com començar el Batxillerat en l'actual Institut Lluís Vives de la capital llevantina. ${ }^{3}$

Ja des de llavors, el jove Querol va començar a destacar en la seua trajectòria acadèmica. El seu pas pel conservatori se salda amb un ple d'excel·lents en totes les assignatures, incloent-hi primers premis en tots els cursos de piano. ${ }^{4}$ Després de finalitzar aquests estudis,

\footnotetext{
1 Traducció del Servei de Llengües i Terminologia (UJI).

2 Arxiu del Conservatori Superior de Música Joaquín Rodrigo de València. Llibre d'actes del curs 1908/09.

${ }^{3}$ Arxiu de l'IES Lluís Vives. Expedients del curs 1916/17. «Q». Expedient Leopoldo Querol Roso.

${ }^{4}$ Residencia de Estudiantes. Arxiu de la JAE. Expedient Leopoldo Querol Roso, JAE/119-9. Conservatori de Música i Declamació de València. Certificació acadèmica datada el 20 de abril de 1927.
} 
dedica el curs 1916-1917 a finalitzar els de Batxillerat, com a pas previ a l'ingrés, el curs següent, a la Facultat de Filosofia i Lletres de la Universitat de València. Allà, el seu expedient torna a ser, de nou, immillorable. Va obtindre matrícula d'honor en totes les assignatures de la llicenciatura, tret d'un únic excel·lent. ${ }^{5}$ En 1921 va obtindre el Premi Extraordinari de Llicenciatura de la Facultat.

Encara que ja hi ha notícies en premsa de concerts de Querol, tant a València com a Vinaròs, durant el seu pas pel Conservatori, l'inici de la seua carrera concertística, pròpiament dita, el podem situar el 12 de maig de 1919 quan, en companyia del violinista Ángel Grande, debuta en l'Ateneu de Madrid, incloent-hi tant repertori per a violí i piano, com una part dedicada al piano només, i que li valgué una primera crítica positiva del més important crític d'aquells anys: Adolfo Salazar. Querol, ja com a solista, debutaria a Barcelona, el 10 d'abril de 1921, i de nou, a l'Ateneu de Madrid, l'11 de febrer de 1922, també amb bones crítiques de Salazar.

Però, sens dubte, més transcendència van tindre els concerts organitzats a València, el 28 de febrer i el 2 de març de 1923, al Teatre Principal, amb l'orquestra dirigida per José Lassalle, tota una novetat ja que en aqueix temps, tal com va indicar Eduardo López Chavarri (1923) en la seua crítica periodística: «Las obras para piano y orquesta no hay costumbre oírlas aquí. Con los dedos de una mano pudieran contarse los conciertos de esa índole que se hayan podido dar en Valencia durante el último siglo [...] Es, pues la presente una gran ocasión para escuchar nuevas y magníficas obras».

No va tindre Querol molt de temps per a assaborir el gran èxit d'aquests concerts ja que, el 15 de març, partia cap a Itàlia per a gaudir d'una beca d'estudis atorgada per la Universitat de València, que li proporcionava la possibilitat d'estudiar a Bolonya un còdex del teòric musical Johannes Tinctoris, semblant al què es trobava a la Biblioteca de la universitat valenciana. Als pocs dies del seu retorn, al maig, va reeditar els èxits amb Lassalle en una sèrie de concerts dins dels actes dedicats a la Coronació de la Mare de Déu dels Desemparats.

Aquest estudi del Còdex de Tinctoris li va mostrar les seues llacunes en paleografia musical medieval, per la qual cosa aprofita la segona part de la seua beca d'estudis per a desplaçar-se a París i així poder estudiar en la Biblioteca Nacional i en la de Santa Genoveva els manuscrits respecte d'això, allà existents. Però, la veritat és que a la capital francesa Querol portarà una doble vida ja que, si bé allí realitza l'intens treball bibliogràfic requerit per la beca de la Universitat, per la seua condició d'intèrpret, es converteix en alumne i deixeble del pianista espanyol més reputat en el París d'aqueixos anys: Ricardo Viñes.

En els anys vint, l'activitat cultural i musical a la ciutat del Sena era impressionant. Amb altres il·lustres valencians allí presents —els germans José i Amparo Iturbi, el borrianenc Abel Mus o, poc després, el compositor Joaquín Rodrigo - va poder viure-la intensament i, més encara, per intermediació de Viñes, conèixer els músics i compositors més importants. ${ }^{6}$

\footnotetext{
${ }_{5}^{5}$ Arxiu Central del Ministeri de Educació. Carpeta 97.250. Expedient personal de Leopoldo Querol Roso. Certificació acadèmica personal datada el 20 de novembre de 1929.

${ }^{6}$ Carta a Eduardo López Chavarri, datada a París el 27 de gener de 1924: «No se puede imaginar lo interesante que es estudiar con Viñes. Ahora está de tournée. Está contentísimo de mí y me ha dado a conocer mucha gente» (Díaz, 1996: II, 146).
} 
El cas més destacat d'això va ser Maurice Ravel, tal com ho indica, en una carta, al seu antic professor López Chavarri (Díaz, 1996: II, 151):

Me he dedicado a estudiar las obras modernas bajo la dirección de los mismos compositores, a fin de que las versiones resulten lo más auténticas posibles. Ya lo he realizado con Ravel ayer en casa de Mme. Sarmento, donde le entretuve toda la tarde, pero es porque toco de él casi toda su producción pianística: ha quedado satisfechísimo, me dedicó todos los ejemplares y recogí escrupulosamente sus preciosas indicaciones.

També en aqueixa dècada de formació, a cavall entre París, Madrid i València, Querol va posar a punt la seua tesi doctoral La poesía y la música del Cancionero de Uppsala, presentada en la Secció d'Història de la Facultat de Filosofia i Lletres de la Universitat Central de Madrid, i defensada el 4 d'abril de 1927; va obtindre no només la qualificació d'excel·lent, sinó també el Premi Extraordinari de Doctorat de la universitat madrilenya. ${ }^{7}$

Però, encara que Leopoldo havia aconseguit debutar, al maig de 1928, fins i tot a la Sala Chopin de la prestigiosa Salle Pleyel de París, la fallida de l'empresa bancària familiar Hijos de Alejo Querol i els consegüents problemes financers familiars, l'arribada de la crisi econòmica provocada pel Crack del 29, i la defunció de son pare, l'encaminaren, amb el canvi de dècada a buscar una estabilitat que passaria, el 1930, per la superació de les oposicions a catedràtic de francès d'Ensenyament Mitjà i, just després, el seu matrimoni amb Manuela Agustín Márquez.

\section{Els daurats anys trenta}

Els anys trenta van suposar un moment daurat no sols en la història de la música espanyola, sinó també en la trajectòria de Leopoldo Querol, que va passar a convertir-se en el pianista de referència en el Madrid d'aqueixos anys. El mateix pianista ja va indicar anys més tard: «es preciso un gran éxito, de amplia resonancia, para que el nombre destaque. Yo lo tuve en mayo de 1932 [...] y constituyó un auténtico acontecimiento musical». ${ }^{8}$

Ravel treballava, des de finals de 1929, en un concert per a piano i orquestra que va ser estrenat al gener de 1932 a la Salle Pleyel, de París. No tenim massa detalls del per què d'aqueixa confluència, però la veritat és que per al 30 d'abril, només tres mesos després, es programa l'estrena espanyola d'aquest concert, al Teatro Español, amb l'Orquestra Filharmònica de Madrid, dirigida per Bartolomé Pérez Casas i un poc conegut Querol com a solista.

La veritat és que l'èxit va ser dels que fan època, i es va crear fins una curiosa unanimitat positiva entre crítics de totes les tendències, des de Salazar fins a Ángel María Castell, que va provocar que, a banda de la repetició del Presto el dia de l'estrena, es programara una nova audició del concert, la setmana següent, de nou, amb gran èxit de públic i crítica; Salazar (1932) va indicar respecte d'això:

\footnotetext{
${ }^{7}$ Arxiu Central del Ministeri d'Educació. Carpeta 97.250. Expedient personal de Leopoldo Querol Roso.

${ }^{8}$ Entrevista realitzada per María Ángeles Arazo per a Las Provincias, en 1968, citada en Sebastián Albiol Vidal (1985: 4).
} 
Se sintió [el públic] tan inflamado de entusiasmo ante el Concierto para piano de Ravel como el día anterior, y puedo asegurar que hubo muchos entusiastas que se acercaron al maestro Pérez Casas para pedirle otra audición más [...]

Esta obra de Ravel es de las que se escucharán forzosamente todos los años. Esperemos, por lo tanto, a una serie que vendrá más tarde, en la que Leopoldo Querol estrenará varios concerti de última hechura.

Però aquest èxit va anar encara més enllà, no passà desapercebut per a la jove generació de compositors espanyols de l'època, que fins aleshores no s'havien provat amb les obres per a piano i orquestra de gran format i que, a partir d'ací, van albirar les possibilitats del gènere, tal com va afirmar el mateix Joaquín Rodrigo després de l'estrena — també per Querol- del seu Concierto heroico: ${ }^{9}$

Tras el éxito del mismo artista con el Concierto de Ravel, de hace diez u once años, y que mereció su consagración, se puso de moda entre nosotros, y aún fuera de nosotros, escribir conciertos para piano. No hubo compositor que, ante aquel triunfo, no pensase tirar su cuarto a espadas contra Querol. Yo, naturalmente, también y primero que nadie.

Aquesta afirmació es veu confirmada pel nombre de concerts escrits en els anys següents per compositors espanyols, estrenats i fins i tot dedicats a Querol; ${ }^{10}$ va inaugurar la sèrie Salvador Bacarisse, amb el concert estrenat per Querol, a qui estava dedicat, amb l'Orquestra Filharmònica de Madrid, dirigida per Pérez Casas, el 21 de desembre de 1933.

Conforme avança la dècada, el prestigi de Querol no fa sinó augmentar. L’èxit, al febrer de 1933, de l'estrena espanyola del Concert núm. 3 de Prokofiev provoca l'organització d'un dinar en honor seu, al madrileny Hotel Nacional, en què s'aplega el més destacat de l'ambient musical de l'època: Bartolomé Pérez Casas, Enrique Fernández Arbós, Julio Gómez, Salvador Bacarisse, Juan José Mantecón, Adolfo Salazar, Víctor Espinós, Regino Sainz de la Maza, Joaquín Rodrigo, Rodolfo Halffter o Antonio de las Heras, entre d'altres. ${ }^{11}$

I és que, si bé els inicis de Querol a Madrid havien estat acompanyats de la Filharmònica de Pérez Casas, prompte va cridar l'atenció de la rival i més important Orquestra Simfònica de Madrid, dirigida per Fernández Arbós, que li reporta nous i importants concerts. Encara més, Arbós era un director amb gran prestigi internacional, la qual cosa li obri les portes del continent, tant com a solista, amb la Simfònica madrilenya, com quan el director és invitat a dirigir orquestres estrangeres, com el cas dels dominicals Concerts Pasdeloup, celebrats al Teatre dels Camps Elisis, de París. Açò també inclou la seua participació en les ambaixades culturals dels distints governs republicans, els exemples més destacats dels quals van ser el concert en l'Exposició Universal de

\footnotetext{
9 Arxiu de la Fundación Victoria y Joaquín Rodrigo. Escritos y comentarios de Joaquín Rodrigo. Carpeta E-2, pàgina 20.

${ }^{10}$ Consta l'estrena per Querol d'almenys trenta concerts per a piano i orquestra, dels que nou són estrenes a Espanya i vint-i-una estrenes absolutes, vuit estan dedicats al propi pianista.

11 «Almuerzo en honor del gran pianista Leopoldo Querol». ABC, 8 de març de 1933.
} 
Brussel-les, de 1935, o el cicle de concerts celebrats en el Col·legi d'Espanya de la Ciutat Universitària de París, en 1936.

Aquest prestigi va desembocar en quelcom certament inaudit i singular, a causa de la forta rivalitat i competència entre aquestes: actuar a finals de $1934 \mathrm{amb}$ les tres principals orquestres madrilenyes amb només sis dies de diferència. Aquesta mostra de la unanimitat del seu pianisme és ben destacada per tota la crítica musical, encapçalada per algú, poc donat a elogis, com Adolfo Salazar, qui indica (1934): «No ha de decirse que las orquestas Sinfónica, Filarmónica y Clásica sientan debilidad o preferencia por este artista. Es que en el momento actual no se ofrece mejor mercancía ni de mayor novedad».

Una mostra del frenètic ritme d'actuacions dutes a terme en aqueixos mesos ens l'aporta el propi pianista en una carta a López Chavarri (Díaz, 1996: II, 157): Ya he actuado con las tres orquestas de Madrid, y aún me falta tocar otra vez con la Sinfónica el próximo domingo en el Monumental el Capricho de Stravinsky. Después nos vamos a Lisboa y después a Zaragoza y al extranjero (Suiza)».

I és que no és atrevit parlar de l'omnipresència de Querol en la major part dels principals esdeveniments musicals que tingueren relació amb el piano durant aqueixos destacats anys de la història de la música espanyola, tant en forma de concerts com en la nova component de concerts radiofònics, amb una important presència en la quasi monopolística emissora Unión Radio, la revista de la qual li va arribar a dedicar fins i tot portades.

Un clar exemple d'aquests importants esdeveniments va ser la visita, al maig de 1935 , a la madrilenya Residencia de Estudiantes del compositor francès Francis Poulenc i de Soulima Stravinsky, pianista i fill del conegut compositor. Aprofitant açò, es va organitzar, per al dia 25, un curiós concert a l'auditori de la Residencia, amb la presència de l'Orquestra Filharmònica de Madrid, dirigida per Gustavo Pittaluga, amb un programa de tres parts en la primera de la qual Soulima va interpretar el Concert per a piano seguit d'orquestra d'harmonia de son pare, en la segona es va realitzar l'estrena espanyola del Concert per a dos pianos i orquestra de Poulenc, amb la participació de Querol al primer piano i el mateix Poulenc al segon ${ }^{12}$ i, finalment, una tercera part on es va interpretar el Concert per a quatre teclats $i$ orquestra d'arc de Johann Sebastian Bach; als quatre pianos hi van estar els ja mencionats Soulima Stravinsky, Francis Poulenc i Leopoldo Querol, als quals se'ls hi va afegir la pianista i compositora Rosa García Ascot.

Aquest important període musical es tanca, per circumstàncies de sobra conegudes, en 1936. Potser l'últim magne esdeveniment va ser l'elecció de Barcelona per a la celebració conjunta, a l'abril d'aqueix any, del III Congrés Internacional de Musicologia i el XIV Festival de la Societat Internacional per a la Música Contemporània. Allà, de nou hi va tornar a participar Querol, amb la Simfònica madrilenya, dirigida per Arbós, amb l'estrena absoluta de l'obra triada pel jurat internacional per a l'esdeveniment: Sinfonía concertante para piano y orquesta de Federico Elizalde.

L'esclat de la Guerra va sorprendre Querol a València, aquest fet el va obligar a passar tota la Guerra a la zona republicana, amb un cert perill per a la seua integritat física ja que,

\footnotetext{
${ }^{12}$ S'hi ha destacat l'anècdota que Querol va executar la seua part de memòria, mentre a Poulenc li va caldre la partitura, la qual cosa va ser comentada a l'auditori jocosament pel propi compositor abans de començar l'actuació.
} 
tot i que no havia ocupat cap càrrec ni s'havia significat políticament, i gaudia d'un gran prestigi i bon nombre d'amistats, era coneguda la seua afinitat ideològica amb el bàndol nacional. ${ }^{13}$ La societat valenciana es va beneficiar d'aquesta presència, ja que es pot dir que la programació de la Societat Filharmònica de València es va sostindre gràcies al pianista, que va participar, entre abril de 1937 i novembre de 1938, en dotze dels vint-iquatre concerts programats, dels quals un total de set van ser consecutius.

\section{Anys de maduresa}

Amb l'entrada de les tropes nacionals a València, les seues simpaties pels nacionals i la seua proximitat amb el ministre d'Educació franquista, José Ibáñez Martín, li permeten superar, sense problemes, la depuració, i més enllà, obtindre, a principis del curs 1939/40 una comissió de serveis al madrileny Instituto Cervantes, la qual cosa li possibilitava ocupar simultàniament una càtedra interina de piano al Conservatori de Madrid, càtedra transformada pocs mesos després en «encarregat de curs de piano», solució donada per l'autoritat educativa perquè pogués esquivar l'evident incompatibilitat entre ambdues dedicacions docents.

És de justícia indicar que, en aquests anys de tanta penúria i dificultats, a la qual cosa s'ha d'afegir la forta repressió política, Querol no va dubtar a fer valdre la seua posició i importants influències dins del nou règim per a ajudar en la mesura que del possible músics amb dificultats polítiques; el cas més evident va ser el del compositor Vicent Garcés, en els primers dies de la caiguda de la València republicana. ${ }^{14}$ Pel que fa a la província, gran importància va tindre en les gestions realitzades perquè l'òpera La filla del Rei Barbut de la llavors jove compositora Matilde Salvador poguera superar, en 1943, la prohibició de l'estrena, dictada per la censura franquista, tal com podem veure en les pròpies paraules de la compositora (Solbes, 2007: 42 i 43):

La censura, que digué "no" sense més justificació ni paper. I quan Leopold Querol, el pianista tan amic dels amics i molt influent als mitjans oficials, va anar a demanar explicacions, li digueren "oficiosament" que la prohibició era pel fet de "ser una òpera en valencià" i, a més a més, "d'una dona i jove" [...] Tot Castelló es va indignar, i l'alcalde, que era el notari Josep Maria Casado, amb Manuel Ballesteros Gaibrois - rector o vicerector de la Universitat de València-, acompanyats per Leopold Querol, anaren a Madrid per tal de gestionar el permís que per fi aconseguiren per a una sola representació.

Dins de la seua carrera docent, Querol obté, el 1942, la seua destinació definitiva a l'Institut Ramiro de Maeztu, centre capdavanter de la nova educació franquista, dirigit

\footnotetext{
${ }^{13}$ El compositor Vicent Garcés fa una excel-lent descripció d'això en el seu dietari: «Els governants republicans coneixen llurs simpaties pels nacionals. Querol renega i estudia. Jo l'ampare quan puc, igual que han fet els compositors madrilenys mentre s'han trobat ací [...] Totes les setmanes done classes de piano, sense acceptar que pague res» (Arrando, 1998: 81, 82).

${ }^{14}$ «Querol ha vingut a vore'm a les 24 hores de produir-se l'entrada de les forces [nacionals]. ¡Noble gest que li agraïxc profundament! [...] Querol i Manolita mantenen viva i tensa la nostra amistança i en totes bandes diuen roses favorables a mi. ¡Gràcies!» (Arrando, 1998: 85, 86).
} 
pels col-laboradors més pròxims d'Ibáñez Martín, on romandrà fins a la jubilació. La simbiosi entre pianista i centre educatiu va ser en benefici d'ambdós, especialment en els primers anys, ja que mentre el pianista obtenia una gran llibertat en dispenses docents per a compatibilitzar la seua carrera interpretativa amb la seua condició de catedràtic de francès, l'Institut guanyava un immillorable organitzador d'activitats i concerts, tant seus com d'uns altres col-legues, i va aconseguir que per la sala d'actes del Maeztu passara la flor i nata de l'ambient musical de la postguerra. ${ }^{15}$

I és que Querol es va convertir en el pianista omnipresent de la primera postguerra, embarcant-se en una sèrie de gires per tota Espanya, encarregant-se de la reactivació de moltes de les societats musicals, tancades des de l'inici de la contesa. Amb tota seguretat, els baixos honoraris que hauria d'obtindre en meitat d'aqueixa crisi humanitària el van portar a ser el pianista amb el nombre més gran de concerts anuals, a localitats de totes les províncies, sense importar-li l'estat de les sales o del mateix piano, sent fins habituals concerts seus amb pianos verticals de més que dubtós manteniment. Va ser just també en aquesta època quan es va reactivar la seua colllaboració amb la Societat Filharmònica de Castelló, que l'anomenarà, el 1951, president honorari i de la qual es convertirà amb els anys en el solista amb nombre més gran de participacions de la història d'aquesta, amb un total de vint-i-quatre.

Però no per això Querol va deixar d'estar present en molts dels principals esdeveniments musicals d'aqueixos anys. Un exemple d'això va ser quan, a semblança del concert realitzat anys enrere a la Residencia de Estudiantes, es va organitzar, al març del 1941, una vetllada al Teatro Colisevm amb la Filharmònica de Madrid, dirigida per César Mendoza Lassalle, i amb quatre parts assignades cada una a un pianista - Luis Galve amb un concert de Mozart, el llavors poc conegut Arturo Benedetti-Michelangeli amb un de Liszt, Querol amb el de Ravel, finalitzant Ricardo Viñes amb les Noches en los jardines de España que Falla li va dedicar- i, per a acabar, una cinquena part on tots van interpretar el Concert per a quatre teclats de Bach.

Tampoc podem oblidar el paper de Querol en els inicis de l'Orquestra Nacional d'Espanya, ${ }^{16}$ participant tant en el concert inaugural, el 25 de juliol de 1940, com en el primer que va donar amb el ja acabat de nomenar director titular, Bartolomé Pérez Casas, el 7 de maig de 1943. Querol també va acompanyar a l'ONE en les primeres gires internacionals d'aquesta, en 1943 i 1944, per Portugal, i es va convertir durant aqueixos anys en el pianista amb més colllaboracions amb aqueixa orquestra.

Aquesta omnipresència de Querol era possible gràcies a una virtut que va ser més que comentada en la seua època: la seua incomparable capacitat memorística i repertorística. Això li permetia gestes tan poc habituals com torejar amb tres actuacions en localitats

\footnotetext{
${ }^{15}$ Mindán, en el seu llibre sobre el Ramiro de Maeztu, indica: «A Leopoldo Querol, gran pianista, le interesaba más dar conciertos de piano que clases de francés. A nosotros nos interesaba también más su contribución a nuestros actos musicales que fueron espléndidos. Para atender en sus deficiencias a las clases de francés se nombraron auxiliares competentes y eficaces» (Mindán, 2001).

${ }^{16}$ Allò cert es que les autoritats franquistes sols desenvoluparen una iniciativa d'orquestra nacional que ja datava de l'època republicana, amb un concert inaugural a Barcelona, el 8 de abril de 1938. I just des de llavors ja s'hi indica una colllaboració de Querol, dins un concert-homenatge a Maurice Ravel després de la seua mort (Franco, 1992: 22).
} 
distintes i amb repertoris distints en menys de vint hores, ${ }^{17}$ interpretar un total de quatre concerts per a piano i orquestra en un únic esdeveniment, ${ }^{18}$ o executar l'obra integral per a piano de Chopin, a l'Ateneu de Madrid, l'abril de 1947, en forma de set concerts de tres parts cada un i de manera consecutiva de dilluns a diumenge, quelcom inaudit, que el va fer aparèixer fins en el conegut NO-DO. ${ }^{19}$

Querol es trobava en un moment dolç; protagonitzava publicitat en els diaris nacionals, o actuava davant de la primera dama argentina, Eva Perón, en la seua visita a l'Alhambra de Granada dins de la seua gira europea. Encara més, les circumstàncies polítiques anaven en favor seu, i va ser nomenat assessor musical de Ràdio Nacional d'Espanya, l'1 de gener de $1947 .{ }^{20} \mathrm{El}$ pianista ocuparà el càrrec fins a 1951, sent la seua faceta més destacada la reconversió de l'agrupació de cambra que hi havia en l'Orquestra Simfònica de Ràdio Nacional d'Espanya, antecessora de l'actual Orquestra Simfònica de RTVE, creada en la dècada dels seixanta.

Però la finalització de la II Guerra Mundial li obria a Querol de nou les portes de França i el continent europeu, després de l'obligada dècada perduda per les conteses civil i mundial. Curiosament, el pianista va tornar a París de la mà de dos compositors coneguts al Madrid republicà i que s'hi trobaven exiliats: Federico Elizalde i Salvador Bacarisse. Sens dubte, un cert atreviment, especialment en el cas d'aquest últim, un furibund antifranquista i comunista, de qui Querol va arribar fins i tot a realitzar estrenes mundials de les seues obres en sòl espanyol.

Aquesta represa relació amb Elizalde també li va facilitar una gira per les Filipines, a l'abril de 1949. Amb gran èxit, Querol va oferir un total de nou concerts, sis com a solista i tres amb la Manila Symphony Orchestra. Precisament, en un d'aquests concerts es va produir l'accidentat debut, com a director de Querol, que va assumir la direcció de l'agrupació des del piano — tal com es deia llavors, «a la Iturbi»—, en sentir-se indisposat el mateix Elizalde ja amb el públic a la sala. L'èxit es va veure engrandit pel gest de Leopoldo, qui aprofitant les seues enormes qualitats pianístiques, va incorporar dins dels seus programes de concert obres dels propis compositors i crítics filipins, va arribar a ser rebut amb tots els honors pel president Elpidio Quirino i, ací a Espanya, va ocupar les portades de diaris nacionals.

\footnotetext{
${ }^{17}$ El 12 de juliol de 1941 Querol va interpretar, junt a l'Orquestra Filharmònica de Barcelona, dirigida per Cèsar de Mendoza Lassalle, un programa per a la Sociedad Filarmónica de Valencia que constaba de tres parts, en la primera de les quals va interpretar el Concert núm. 1 de Mendelssohn, en la segona el Concert per a mà esquerra de Ravel i el Concerto núm. 1 de Liszt i, en la tercera, el Concert núm. 2 de Rachmaninov.

18 «Desplazándose en su propio automóvil, actuó la tarde del 9 de diciembre de 1944 en Alcoy, por la noche en Onteniente y, tras llegar a su domicilio valenciano a las cuatro de la madrugada, a la mañana siguiente junto a la Orquesta Municipal de Valencia en el Teatro Principal» (Chavarri, 1944).

${ }^{19}$ Hi ha una descripció del fragment en la web de l'Ateneu de Madrid (20 de juliol de 2012): <http://archivo. ateneodemadrid.es/actuaci-n-del-pianista-leopoldo-querol;isad>.

${ }^{20}$ A això no se li pot sostreure la qüestió política. Després de la II Guerra Mundial, Franco, amb la finalitat de suavitzar les relacions amb les potències vencedores, decideix que el control de l'aparell de propaganda i mitjans de comunicació passe dels falangistes, més propers a les potències feixistes, als menys significats catòlics. Quan, en 1946, els homes d'Ibáñez Martín prenen el control, substitueixen un gran nombre de càrrecs, incloent-hi aquesta assessoria musical, que passa del compositor Joaquín Rodrigo, íntim del falangista Antonio Tovar, per l'afí Leopoldo Querol, fet que va enemistar pianista i compositor durant dècades, i va propiciar que Rodrigo li retirara la dedicatòria del Concierto heroico.
} 
Però, malgrat aquesta reeixida carrera i que Querol es trobava encara en plenes facultats físiques, a partir dels anys cinquanta la importància dels seus concerts decreix. Açò es pot deure a raons que poden anar des de picabaralles o gelosies professionals, potser aguditzades pel seu pas per l'Assessoria de Música, fins a la seua poca adaptació a les noves corrents interpretatives. L'estil de Querol estava pròxim al que Jürg Stenzl va qualificar en 1995 com a «interpretació expressiva», estil prou lliure que busca aprofundir en l'expressivitat musical de la composició, sense que per a aconseguir tal fi dubtara a afegir recursos expressius no indicats pel compositor, o exagerar l'espectacularitat de passatges virtuosístics, encara a costa de collir alguns errors o notes falses. Aquest estil va començar a casar malament amb la nova estètica interpretativa predominant després de la II Guerra Mundial, la qual cosa el va portar a perdre ràpidament terreny respecte a pianistes de la següent generació com Alicia de Larrocha, Esteban Sánchez o Joaquín Achúcarro, amb interpretacions molt més nítides i contingudes.

Aquesta pèrdua d'influència a Espanya es veu compensada amb la seua contínua presència a sales parisenques com la Gaveau, on es va convertir en una referència quant a la interpretació de música espanyola, ${ }^{21}$ la qual cosa li permet gravar, en 1954, per al segell Ducretet-Thomson, gràcies al recentment comercialitzat format long play, la integral de la Suite Iberia, d'Albéniz; es convertia així en el primer pianista a registrar aquesta obra capital del repertori espanyol. ${ }^{22}$

I és que Querol sempre va estar atent al poder publicitari dels mitjans de comunicació, tal com va indicar en nombroses entrevistes al llarg de la seua carrera. Si ja als anys trenta havia destacat amb les seues participacions en Unión Radio, i en els quaranta en Ràdio Nacional d'Espanya, en els cinquanta no va dubtar a participar fins en una pel-lícula, Concierto mágico, interpretant-se a si mateix, ${ }^{23} \mathrm{i}$ en els albors de la televisió, tant espanyola com francesa.

\section{4. Últims anys}

Querol va allargar la seua carrera docent a l'institut Ramiro de Maeztu fins a l'octubre de 1966, quan, pròxim als seixanta-set anys va sol-licitar la jubilació. A partir d'aquesta data va prosseguir amb la seua carrera interpretativa i va reprendre i va finalitzar els seus estudis musicològics, començant amb el seu estudi sobre el manuscrit de Tinctoris, que li va valdre una beca de la Fundación Juan March, i finalitzant amb la publicació, en 1980, dels seus

\footnotetext{
${ }^{21}$ Informació corroborada per l'estudi de la pròpia premsa musical parisenca i la comparació dels preus d'entrades als concerts, o també pel compositor vinarossenc Carles Santos, en aqueixos anys un jove estudiant a París, qui en entrevista personal em va indicar el cert èxit que tenien els esmentats concerts.

${ }^{22} \mathrm{~S}$ 'hi ha aportat la data de 1954 per ser la indicada en la reedició digitalitzada d'aquest doble disc, realitzada per EMI en 2006, amb el títol de Les Rarissimes de Leopoldo Querol, i que va obtindre el premi Diapason d'Or en la categoria de Le coin du collectionneur. Però allò cert és que podem sospitar que la gravació s'havia realitzat ja en 1952, en aparèixer en els cartells del seu concert a la Salle Gaveau, del 18 de novembre de 1952 - justament amb la integral de la Iberia- «enregistré sur Disques Ducretet-Thomson». En tot cas, qualsevol de les dues dates la segueix convertint en la primera gravació de l'obra, que s'anticipa en quasi deu anys a la d'Alicia de Larrocha.

${ }^{23}$ Existeix, per a l'estudi, una còpia de la pel-lícula a l'arxiu de la Filmoteca de Catalunya. Així mateix, en Internet pot trobar-se una fitxa tècnica del film (20 de juliol de 2012): <http://www.imdb.com/title/tt0044512>.
} 
estudis definitius sobre el Cançoner d'Uppsala, actualment més conegut com el Cançoner del Duc de Calàbria. També va aprofitar per a esgotar el seu vessant bibliogràfic, sumant als seus llibres pedagògics de llengua francesa i a la primera part de la seua Breve historia de la música, publicats en la dècada dels cinquanta, una segona part que va tancar aquest recorregut historicomusical i on, lògicament, comptem amb l'interès afegit de llegir la seua anàlisi de compositors que va conèixer molt bé i fins d'obres que ell mateix va estrenar. ${ }^{24}$

També en aquests anys augmenta la seua nòmina de premis i reconeixements; va obtindre entre altres la Gran Creu d'Alfons X el Savi, en 1966, que se sumava a la Creu de Plata d'Alfons XII, ja atorgada en 1930. També es converteix, en 1969, en el primer acadèmic a inaugurar la nova Secció de Música de l'Acadèmia de Belles Arts de Sant Carles de València, investidura a la qual es va sumar, en 1972, la de la Reial Acadèmia de Belles Arts de Sant Ferran de Madrid, de la qual va ser, fins a la seua defunció, secretari de la Secció de Música. ${ }^{25}$

La seua jubilació també va comportar una major relació amb la província de Castelló. La fallida de l'empresa familiar havia provocat la seua desvinculació amb el seu Vinaròs natal, però l'elecció des de 1933 de Benicàssim com el seu lloc de descans estival, adquirint a l'efecte una vil-la la qual li va posar el nom de la seua esposa, Vil·la Manuela, el va mantindre sempre pròxim a la província, amb les seues actuacions anuals per a la Societat Filharmònica de Castelló, el Cercle Medina de la localitat, o fins a la Banda Municipal.

En 1951 es va produir el retrobament oficial entre Querol i Vinaròs, localitat que li va atorgar el títol de Fill Predilecte i, amb els anys, va posar el seu nom a una avinguda i al mateix Institut d'ensenyament mitjà.

Però la seua relació especial amb Benicàssim es va estretir encara més just en aquests anys, quan la iniciativa turística d'organitzar un concurs de guitarra que tinguera el nom del conegut guitarrista castellonenc Francisco Tárrega va ser presa amb gran interès per Querol, qui es va convertir des de llavors en el seu factòtum. A l'agost de 1967 va tindre lloc la primera edició, amb un tribunal presidit pel pianista, a l'igual que la pràctica totalitat de totes les posteriors mentre la seua salut li ho va permetre.

I és que, al llarg dels anys següents, passaran pel jurat del Tárrega guitarristes com Regino Sainz de la Maza, Narciso Yepes, Rafael Balaguer, Manuel Cubedo i David Rusell, directors com Juan Pich Santasusana i Alberto Blancafort, o compositors com José Muñoz Molleda, Federico Moreno Torroba, Vicente Asencio, Matilde Salvador, Ernesto Halffter i Joaquín Rodrigo, arribant moltes vegades a produir-se les deliberacions al porxe de la pròpia Vil·la Manuela de Querol.

Aquesta relació amb Benicàssim i el seu paper en l'èxit del certamen de guitarra va culminar amb el seu nomenament, en octubre de 1981, com a Fill Adoptiu de la localitat,

\footnotetext{
${ }^{24}$ Ací podríem incloure també la seua breu faceta compositiva, amb alguns esborranys de joventut, però només plasmada oficialment en dues composicions que, tot i que ja interpretades al llarg de la seua carrera en alguns concerts, especialment com a afegits al programa, foren definitivament publicades per Unión Musical en 1964: el Preludio i la Danza valenciana.

${ }^{25}$ Podríem afegir-hi el nomenament com a acadèmic corresponent de les de Santa Isabel d'Hongria de Sevilla, de la de Ciències, Belles Lletres i Nobles Arts de Còrdova, de la Jerez de la Frontera o la de Belles Arts de Sant Jordi de Barcelona.
} 
així com la dedicatòria d'un cèntric carrer en homenatge. ${ }^{26}$ Querol va estar en el jurat del certamen fins a l'edició de 1982, i en la següent va ser nomenat president d'honor.

Però la relació entre Querol i el Certamen de Guitarra Francisco Tárrega va arribar fins a les últimes conseqüències, sent el trist protagonista de l'edició de 1985, quan el 26 d'agost, coincidint amb l'inici de la primera sessió, moria a pocs metres d'allà, a la seua estimada Villa Manuela. Després de comunicar la trista notícia el seu amic i administrador José Luis Tárrega, es va interrompre breument l'eliminatòria, i se li va dedicar un minut de silenci que va finalitzar amb una clamorosa ovació (Tárrega, 2006: 161).

La defunció de Querol va ocupar espai en els mitjans nacionals i bona part de la portada dels dos diaris locals castellonencs; el seu funeral es va celebrar a l'església de Sant Tomàs de Benicàssim, i el seu fèretre fou traslladat, posteriorment, a València on descansa, des de llavors, al Cementeri Municipal en un nínxol sense cap làpida. ${ }^{27}$

\section{Conclusió}

Si ja en 1939 la premsa nacional indicava que Querol era un pianista de la labor del qual no en parlaria només la generació que l'havia escoltat, sinó que era un artista d'aquells que «fuerzan el tiempo, y el eco de su fama llega a los que aún no han nacido», ${ }^{28}$ a la qual cosa cal sumar l'important espai dedicat a la seua defunció i funeral en els diaris castellonencs, fa a penes vint-i-set anys, sorprèn més encara la poca valoració actual de la seua figura.

Alumne brillantíssim, podem situar-lo dins de la generació musical del 27, tant per trajectòria biogràfica com per la seua àmplia formació intel·lectual, incloent-hi un ampli coneixement del llatí que va permetre les seues investigacions musicològiques sobre còdexs llatins musicals, especialment el de Tinctoris, present a la Universitat de València, i sobre el Cançoner del Duc de Calàbria, encara que - certament - el procés va ser força llarg, a causa de les seues múltiples obligacions, i la tardana publicació del seu treball definitiu sobre aquest últim li va restar gran part de la seua efectivitat.

A nivell interpretatiu, va ser un pianista amb unes impressionants facultats repertorístiques i memorístiques, que li van permetre gestes avui en dia impossibles de veure en qualsevol esdeveniment o cicle de concerts. La seua estètica interpretativa, certament desfasada respecte als cànons actuals, més pròxima als pianistes de principis del segle xx que de l'estil més objectiu triomfant després de la II Guerra Mundial, va fer que encara que es convertira en el pianista de referència en l'Espanya dels anys trenta $\mathrm{i}$ quaranta, a partir dels cinquanta la seua carrera interpretativa fóra allunyant-se poc a poc dels esdeveniments de major importància i, més encara, que grans èxits com la primera gravació de la integral de la Suite Iberia, d’Albéniz, siguen avui en dia a penes coneguts o tractats fins en publicacions bibliogràfiques de referència sobre aquesta obra.

Però també és cert que no podem oblidar la seua labor com a pianista d'estrena d'obres de gran part dels compositors espanyols de la seua generació, labor en pro de la música

\footnotetext{
${ }^{26}$ Arxiu Municipal de Benicàssim. Acta de la sessió ordinària en primera convocatòria corresponent al dia 26 d'octubre de 1981. Punt 7è.

${ }^{27}$ Cementeri Municipal de València, nínxol senzill en la secció cinquena dreta, grup A, tramada 3, número 0438.

${ }^{28}$ Hoja del Lunes, 24 de juliol de 1939.
} 
de la seua època per la qual va rebre nombroses alabances, però que avui en dia té poca transcendència per trobar-se la immensa majoria d'aqueixes obres fora del repertori habitual dels intèrprets.

Tampoc podem oblidar en la seua carrera pianística que la seua labor, i la poca exigència que va manifestar a actuar en localitats i sales de menor envergadura, va permetre que per primera vegada molts dels aficionats a la música pogueren escoltar obres avui en dia més que habituals. Això va ser encara de més transcendència en un gènere com el de piano i orquestra, no dubtant fins i tot a actuar amb bandes de música locals, permetent, com en el cas de Castelló, que els seus habitants pogueren escoltar per primera vegada obres com el Concert de Schumann, el de Grieg o els segons concerts de Brahms o Rachmaninov.

I és que aquesta importància de la seua figura és més evident encara quan parlem de la província de Castelló, tant per haver-hi nascut i morir, com pel gran nombre de concerts realitzats ací, el gran suport que sempre va donar a les associacions i músics locals i, finalment, per la seua relació amb Benicàssim, culminada amb el Certamen Internacional de Guitarra Francisco Tárrega.

\section{BIBLIOGRAFIA}

$A B C$ (1933): «Almuerzo en honor del gran pianista Leopoldo Querol», 8 de març.

AuUntament de BenicÀssim: Arxiu municipal.

Albiol Vidal, S. (1985): «Leopoldo Querol en el recuerdo», Vinaròs, 31 d'agost.

Arrando, S. (1998): El compositor Vicent Garcés i Queralt (1906-1984), Fundació Bancaixa, Sagunt. ATENEO DE MADRID (2012): <http://archivo.ateneodemadrid.es/actuaci-n-del-pianista-leopoldo-querol;isad>.

Chavarri, E.L. (1944): «La Orquesta Municipal.- Un record de Leopoldo Querol: Alcoy, Onteniente y Valencia en menos de 24 horas», Las Provincias, 13 de desembre.

Conservatori de Música i Declamació de València: Arxiu.

Conservatori Superior de Música Joaquín Rodrigo de València: Arxiu.

Díaz Gómez, R. i V. Galbis López (1996): Eduardo López Chávarri Marco. Correspondencia, Conselleria de Cultura, Educació i Ciència, València.

FRAnco, E. (1992): Memoria de la Orquesta Nacional de España 50 aniversario, Instituto Nacional de las Artes Escénicas, Madrid.

FundACIÓN VICTORIA Y JOAQUín RodRIGO: Archivo.

Institut d'Ensenyament Secundari Lluís Vives de València: Arxiu.

HoJA DEL LunEs (1939): 24 de juliol.

LóPez Chávarri, E. (1923): «Lassalle y Querol», Las Provincias, 27 de febrer.

Masó Agut, M. (2012): La vida y la obra del pianista Leopoldo Querol Roso (1899-1985). Análisis histórico, cultural y social del personaje y su época, tesi doctoral dirigida pel doctor Juan José Ferrer Maestro, presentada en el Departament d'Història, Geografia i Art de la Facultat de Cièncias Humanes i Socials de la Universitat Jaume I i llegida el 28 de juny de 2012.

Mindán Manero, M. (2001): Historia del Instituto Ramiro de Maeztu de Madrid, Sociedad Coop. de Artes Gráficas, Saragossa.

Ministerio de EduCACión: Archivo Central.

Peris Domínguez, J. i V. Calduch Bellido (2008): Sociedad Filarmónica de Castellón, memoria de mil conciertos, Servei de Publicacions, Diputació de Castelló, Castelló.

Querol Roso, L. (1971): «Evocación de mi infancia», Vinaroz, 23 de juny.

REsidencia de Estudiantes: Archivo.

Salazar, A. (1932): «Orquesta Filarmónica. Una suite de J. Bautista», El Sol, 8 de maig.

- 1934: «Querol, en las tres orquestas. Obras de Gomá, Bacarisse, etc.», El Sol, 4 de desembre. 
SAPENA, S. (2007): La Sociedad Filarmónica de Valencia (1911-1945): origen y consolidación, tesi doctoral dirigida pel doctor. Vicente Galbis López, presentada en el Departament de Comunicació Audiovisual i Història de l'Art de la Facultat de Belles Arts de la Universitat Politècnica de València,

Solbes, R. (2007): Matilde Salvador. Converses amb una compositora apassionada, Tàndem Edicions, València,

STEnZL, J.T. (1995): «In Search of a History of Musical Interpretation», The Musical Quarterly, 79 (4), 683-699.

Tárrega Queral, D. (2006): Certamen Internacional de Guitarra "Francisco Tárrega". Benicàssim 1967-2005, Castelló, Domingo Tàrrega Queral.

\section{BIONOTA}

\section{Mario Masó Agut}

Natural de Castelló, va començar els seus estudis musicals en el Conservatori de la seua ciutat natal, finalitzant-los en els conservatoris superiors de Barcelona i Múrcia, on va obtindre els títols de Professor Superior de Piano i Música de Cambra. És llicenciat en Història i Ciències de la Música, i doctor per la Universitat Jaume I, amb una tesi doctoral sobre el pianista vinarossenc Leopoldo Querol Roso i la seua època. Des de 1994 ha sigut professor dels conservatoris professionals de música d'Elx, la Vall d'Uixó i Castelló, centre on actualment exerceix, per oposició, com a professor de piano. 